\title{
Integration of normalised different vegetation index and Soil-Adjusted Vegetation Index for mangrove vegetation delineation
}

\begin{abstract}
Discriminating between vegetation and non-vegetation areas is of crucial importance in the study of mangroves. This will help mangrove monitoring and management since losses and degradation of the mangroves are reported to be substantial in recent years. This study investigates the integration of Normalised Difference Vegetation Index (NDVI) and SoilAdjusted Vegetation Index (SAVI) as a tool to discriminate vegetation covers in the mangrove forest. High resolution remotely sensed images from Satellite Pour 1'Observation de la Terre (SPOT-6 and SPOT-7) satellite, with $1.5 \mathrm{~m}$ spatial resolution over the Matang Mangrove Forest Reserve (MMFR) was acquired. A complete ground-truthing was conducted at the preliminary stages of land cover classification. A Moran's I analysis shows a random pattern of groundtruthing; (Kuala Sepetang; p-value $=0.219$; Kuala Trong, p-value $=0.163$; Sungai Kerang, pvalue $=0.159$ ). Since $S A V I$ requires a suitable $L$-factor to be used to distinguish the vegetation areas, four different L-factors viz. 0.1, 0.25, 0.5 and 0.75 were tested, and the multiple linear regressions, using the stepwise regression method of backward elimination, found that the Lfactor 0.75 was significant to be used for MMFR. A correlation analysis conducted between the results of NDVI, SAVI and supervised classification shows a high significant relationship, especially between NDVI and SAVI (0.991) at 99.99\% level. This shows that NDVI and SAVI are useful analyses that can be employed to improve the accuracy of classification in the mangroves.
\end{abstract}

Keyword: Vegetation indices; Mangrove; Supervised classification; Geospatial technology; Matang mangrove forest 